\title{
PROTECCIÓN PENAL DE LOS DERECHOS HUMANOS DE LOS MENORES TRABAJADORES EN MÉXICO*
}

\author{
CRIMINAL PROTECTION OF HUMAN RIGHTS \\ OF YOUNG WORKERS IN MEXICO \\ PRO'TEÇAO PENAL DOS DIREITOS HUMANOS \\ DOS MENORES TRABALHADORES NO MÉXICO
}

\author{
Isaías Jorge Acata Águila a \\ dr.acata@live.com.mx \\ Recibido: 15 de Febrero 2013 \\ Aceptado: 04 de Junio 2013
}

\begin{abstract}
El niño es como un barro suave donde puedes grabar lo que quieras... pero esas marcas se quedan en la piel... Esas cicatrices se marcan en el corazón... Y no se borran nunca.
\end{abstract}

\section{RESUMEN}

La explotación laboral infantil es una conducta antisocial grave. Una serie de estudios realizados en 2009 -año internacional del niño-, mostraron que hay más de 80 millones de niños menores de 12 años que desempeñan multitud de trabajos en condiciones infrahumanas, la mayoría viven en países de América Latina, (México) África y Asia. Sus escasos ingresos (no salarios) son imprescindibles para la supervivencia de sus familias, y tan solo sirven para satisfacer las necesidades más urgentes: alimentación, vivienda y ropa en forma muy precaria.

El combate contra la explotación laboral infantil requiere una acción inmediata, general y constante. La Convención de

\footnotetext{
* El presente artículo está asociado a investigación científica, teniendo en cuenta que presenta de manera particularizada resultados derivados de proyectos de investigación en derecho y ciencias sociales ya terminados, con los cuales se da una nueva visión del problema del trabajador menor de edad en la República de México.

a. Profesor de tiempo completo de la Universidad Autónoma de Morelos. Abogado, Maestro en Ciencias Penales y Doctor en Derecho de la Universidad Autónoma de Puebla. Notario. Conferenciante. Articulista. Ponente nacional e internacional. Tratadista.
} 
Naciones Unidas en 1999 al tratar el tema: Las Peores Formas de Trabajo Infantil, vinculó a los gobiernos de los Estados parte a respetar, proteger y promover a la infancia, como elemento clave para el desarrollo social. Sin embargo es muy frecuente que los gobiernos se nieguen a admitir que existan problemas en sus países sobre la explotación infantil. En México empresas nacionales e internacionales utilizan a menores de doce años, sin pagarles el sueldo mínimo y menos las demás prestaciones de Ley, quienes tienen que conformarse con las propinas de los clientes.

El abuso laboral del menor constituye una violación grave de los derechos humanos, que debe ser sancionada por el derecho penal, con un tipo especial que prevea una sanción particularmente sensible, que desaliente la explotación laboral de los menores trabajadores, en todos los países, explotación que impide que no reciban salarios y prestaciones de ley. Solo por ser menores.

\title{
PALABRAS CLAVE
}

Derecho, Menor, Trabajador, Abuso, Violación Explotación, Pena.

\begin{abstract}
The child labor is a serious antisocial behavior. A series of studies conducted in 2009 -international year of the child -, showed that more than 80 million children under 12 who perform many jobs in sweatshops, most live in Latin American countries (México) and Africa, Asia. Their low income (not wages) are essential for the survival of their families, and only serve to satisfy the most urgent needs: food, shelter and clothing in very precarious.

The fight against child labor requires immediate action, general and constant. The UN Convention in 1999 to address the issue: The Worst Forms of Child Labor, linked to the governments of the States Parties to respect, protect and promote childhood, as a key element for social development. However it is very often that governments refuse to admit that there are problems in their countries on child exploitation. In Mexico national and international companies used under twelve years without paying the minimum wage and other benefits under law, those who have to comply with the tips from customers.

The child labor abuse constitutes a serious violation of human rights, which must be sanctioned by criminal law, with a special type that provides a penalty particularly sensitive to discourage labor exploitation of child workers in all countries, avoiding who do not receive wages and benefits law. Just to be minors.
\end{abstract}

\section{KEYWORDS}

Law, Minor, Worker, Abuse, Rape, Exploitation, Penalty. 


\section{RESUMO}

A exploração do trabalho infantil é uma conduta anti-social grave. Uma série de pesquisas feitas em 2009-ano internacional da criança-mostraram que tem mais de 80 milhões de crianças menores de 12 anos que desempenham multidão de trabalhos em condições sub-humanas, a maioria moram em países de Latino-américa (México), África e Ásia. Suas rendas escassas (não salários) são imprescindíveis para sobrevivência de suas famílias, e só servem para satisfazer as necessidades mais urgentes: alimentação, moradia e roupa de maneira precária.

O combate contra a exploração do trabalho infantil exige uma ação imediata, geral e constante. A Convenção das Nações Unidas de 1999 ao se referir ao tema: As Piores Formas de Trabalho Infantil, vinculou aos governos dos Estados parte a respeitar, proteger, e promover à infância, como elemento chave para o desenvolvimento social. No entanto, é muito frequente que os governos se recusem a admitir que existam problemas nos seus países sobre a exploração infantil. No México empresas nacionais e internacionais usam menores de doze anos, sem pagar o salário mínimo e menos as prestações de Lei, quem tem que se conformar com as gorjetas dos clientes.

O abuso trabalhista do menor constitui uma infração grave dos direitos humanos, que deve ser multada pelo direito penal, com um tipo especial que preveja uma sanção particularmente sensível, que desestimule a exploração trabalhista dos menores trabalhadores, em todos os países, evitando que não recebam salários e prestações de lei. Só por ser menores.

\section{PALAVRAS-CHAVE}

Direito, Menor, Trabalhador, Abuso, Violação, Exploração, Pena.

\section{INTRODUCCIÓN}

Comenzaremos esta investigación con una pregunta: ¿Los trabajadores menores de edad, son empleados o son esclavos? Las grandes empresas nacionales e internacionales en México y en la gran mayoría de países pobres (aunque no están exentos los países ricos) se aprovechan de la mano de obra barata o regalada de los menores de edad, sin proporcionarles los estándares mínimos de prestaciones legales, como: salario mínimo, seguro social, vacaciones, aguinaldos, capacitación para el trabajo, protección a trabajos de riesgo etc., que por ley les proporcionan a los trabajadores adultos; además si algún trabajador adulto no recibe por lo menos el salario mínimo por su trabajo diario subordinado, la Ley Federal del Trabajo en México lo tipifica como delito. ${ }^{1}$ Sin embargo, los menores trabajadores utilizados por estas grandes empresas (algunas ni tan grandes, pero si abusivas) los ocupan como empleados no asalariados, y estos menores tienen que conformarse con las propinas de los clientes de estas empresas abusivas. Burlando el interés superior del menor, el espíritu protector de la ley y de la sociedad, además de que son señalados con los sobrenombres peyorativos de: "cerillos", "chalanes", "ayudantes", etc.,

\footnotetext{
1. Vid. Artículo. 1004 de la Ley Federal del Trabajo. Cámara de Diputados del H. Congreso de la Unión, México. 2012, p. 224. "Al patrón de cualquier negociación industrial, agrícola, minera, comercial o de Servicios, que haga entrega a uno a o varios de sus trabajadores de cantidades inferiores al salario fijado como mínimo general, o haya entregado comprobantes de pago que amparen sumas de dinero superiores de las que efectivamente hizo entrega, se le castigará con las penas siguientes:..."
} 
nunca como trabajadores, lo que constituye una especie de discriminación, vulnerando desde un principio sus derechos humanos.

El Fondo de Naciones Unidas para la Infancia (UNICEF) considera el trabajo de los empacadores de las tiendas de autoservicio, como una de las actividades clasificadas como de explotación infantil por las empresas y los particulares. ${ }^{2}$ Tan sólo en la Ciudad de México hay unos 190 mil menores de edad que trabajan como empacadores en tiendas de autoservicio, a quienes no se les paga ningún salario, violando los derechos fundamentales de estos menores, derechos consagrados en la constitución mexicana, y en los tratados internacionales, ${ }^{3}$ no tienen contrato laboral y ninguna prestación, sólo reciben propinas de los clientes, "limosnas". La mayoría trabaja sin sueldo, lo que afecta su patrimonio y desarrollo social, escolar, y cultural; autoridades, empresas y sociedad se desentienden de su situación. La Organización Internacional del Trabajo (OIT) considera este abuso laboral como explotación infantil, ya que no tienen contrato de trabajo, sueldo base, ni prestación alguna; no obstante, son obligados por los empleadores a cumplir requisitos formales como si fueran trabajadores asalariados: cubren horarios, cumplen responsabilidades y hasta son "castigados" si infringen las reglas, obligándolos a desempeñar tareas que corresponden a un trabajador adulto que sí recibe sueldo y demás prestaciones.

\section{PROBLEMA DE LA INVESTIGACIÓN}

La protección de los derechos humanos es fundamental para el desarrollo integral de todas las personas menores o adultas, y en consecuencia de las sociedades en el mundo, y con mayor razón lo es la protección de los derechos humanos de los menores trabajadores. Las previsiones administrativas y laborales para impedir la explotación infantil han sido insuficientes para disminuir el abuso laboral a menores. La falta de tipificación de la explotación laboral a los menores, cometidas por grandes empresas nacionales e internacionales que se ven beneficiadas por el trabajo de menores de doce años, sin que les paguen el salario mínimo establecido por la ley laboral, y tampoco les otorguen las demás prestaciones que rigen por ley, trae como consecuencia que prolifere el abuso laboral a los menores por estas empresas, sometiéndoles a una explotación inhumana, muy parecida a la esclavitud, quienes por su necesidad económica deben conformarse con las propinas (limosnas) de los clientes para su subsistencia. Surge entonces la necesidad de tipificar esta conducta.

\section{HIPÓTESIS}

Se funda en la conveniencia de la aplicación de la norma penal para prevenir la explotación laboral infantil en México, y muchos países subdesarrollados y aun los desarrollados. Ya que esta norma busca la prevención de las conductas antisociales, en primer término, y en segundo la reparación del daño material y moral.

\footnotetext{
2. PROTECCIÓN INFANTIL. Contra el Abuso y la Violencia: "Se calcula que en todo el mundo hay 158 millones de niños y niñas de entre 5 y 14 años que trabajan, lo que equivale a 1 de cada 6 niños y niñas en condiciones de peligro."

http://www.unicef.org/spanish/protection/index_childlabour.html. Consultada el 25 de marzo de 2013.

3. Vid. Artículo 5․ Constitución Política de los Estados Unidos Mexicanos, Cámara de Diputados del H. Congreso de la Unión, México, 2013 p. 6. Párrafo, $3^{\circ}$. "Nadie podrá ser obligado a prestar trabajos personales, sin la justa retribución y sin su pleno consentimiento...."
} 
Se analizó y comprobó la utilidad jurídica-penal para proteger los derechos humanos de los menores trabajadores con la norma penal, procurando el objetivo principal de preservar el normal desarrollo bio-psico-social de los menores trabajadores.

\section{METODOLOGÍA}

En la presente investigación se utilizaron los métodos: inductivo-deductivo, analíticosintético, comparativo y dogmático. Con técnicas de investigación documental.

\section{OBJETIVOS}

Objetivo principal. Se busca analizar, comprender y proponer la mejor forma de protección de los derechos humanos de los menores trabajadores; encontrar, analizar y combatir a través de las normas penales las causas por las cuales los menores son explotados por los patrones que, como personas físicas y morales, se aprovechan de su trabajo, utilizándolos en su beneficio, obteniendo un trabajo subordinado que les provee beneficios económicos, al no pagar ningún salario o salarios inferiores al que se paga a los trabajadores adultos.

\section{OBJETIVOS PARTICULARES}

a) Encontrar la explicación de la explotación infantil por los patrones que se aprovechan de un trabajo subordinado, sin pagar el salario mínimo adecuado.

b)Analizar la eficacia de las normas jurídicas distintas a las penales que tratan de combatir la explotación laboral infantil.

c) Comparar las formas de explotación infantil en México, y en los países subdesarrollados, y aun en los países desarrollados.

\section{RESULTADOS:}

De la anterior investigación resultó:

a) No son suficientes las disposiciones legales laborales para impedir la explotación infantil en México, cuando se emplea y se utiliza a menores y no se les paga ningún sueldo, ni siquiera el salario mínimo; así como tampoco se les otorga las prestaciones laborales previstas en la ley laboral para los trabajadores adultos.

b)Es necesario acudir a la última razón de Estado (derecho penal) para prevenir y erradicar la explotación de los menores trabajadores por empresas nacionales e internacionales, personas físicas y morales, que no respetan las leyes laborales, nacionales e internacionales.

c) Hay la necesidad social nacional e internacional de tipificar, en todos los países que firmaron la Convención Internacional de Derechos de los Niños, esta conducta explotadora del menor trabajador como delito: "estableciendo que será sancionado con prisión y multa 
(determinada por cada país) a toda persona física y moral que en forma personal o a través de sus representantes legales utilice, emplee, use, aproveche, explote, ponga a trabajar en sus empresas o a su servicio a menores de dieciocho años y no les pague el salario mínimo o el salario que le pagaría a un adulto por esa misma actividad; o no les proporcione todas y cada una de las prestaciones laborales establecidas en las leyes nacionales, o en los Tratados Internacionales en los cuales México sea parte.

d)La sanción se debe agravar cuando el sujeto activo de este delito se aproveche del trabajo de tres o más menores, so pretexto de que los utilizó para beneficiar al menor con las propinas, dádivas o limosnas que recibieron de los clientes.

\section{LOS DERECHOS HUMANOS DE LA NIÑEZ}

¿Por qué proteger a la niñez? La respuesta se funda en la permanencia y progreso de la humanidad. Está probado que entre el primer y tercer año se forma la personalidad del niño; en este lapso se sientan las bases del aprendizaje, estableciendo las características de la personalidad que nos acompañarán hasta la muerte. Antes de cumplir un año el menor reconocerá sin problemas un "no rotundo" o un "sí claro", que le indican su forma de comportamiento dictada por sus padres o sus tutores, después empezará a evaluar las normas que rigen su comportamiento. Para educar a un niño (no solo con el aprendizaje) los padres deben transmitir ciertos tipos de comportamientos aceptables o inaceptables.

Así, en la categoría de lo estrictamente prohibido se deben fijar las conductas que hacen daño a otras personas, y aceptar las que benefician. Adriana Fazzio y Jorge Sokolovsky, en un análisis histórico de la situación política y social de Argentina en los últimos años, ofrecen un diagnóstico social de la infancia en su país, con un análisis crítico de las políticas aplicadas, formulando propuestas y procedimientos, utilizando el trabajo social, la psicología, la sociología y las ciencias jurídicas. El aporte más significativo, al parecer, es la reflexión acerca de la responsabilidad en la respuesta del Estado y la sociedad ante el debilitamiento de la familia y la desprotección de los niños ${ }^{4}$. Por donde quiera que dirijamos nuestra reflexión, encontramos que los menores son los hombres y mujeres que guiarán a las sociedades en la próxima década, entonces se puede apreciar que los menores son, disculpando la expresión, el futuro cuasi presente de la humanidad. Hacia ellos debemos orientar todos nuestros esfuerzos para subsistir como entes humanos racionales. Esbocemos ahora la disyuntiva de a quién corresponde la responsabilidad cuando no se garantiza el pleno ejercicio de los derechos del niño: ¿Será solo el Estado? O ¿También lo será la sociedad civil? ¿Y cuáles serán las medidas más oportunas para proteger a los menores de los abusos de los mayores? Creemos que todos somos responsables cuando se afectan los derechos de los menores, porque es nuestra semilla que debe germinar en las mejores condiciones de desarrollo.

La primera preocupación internacional por la situación de la niñez se produjo en 1923, cuando el consejo de "Save the Children International Union", adoptó una declaración de cinco puntos sobre los derechos del niño, conocida como la Declaración de Ginebra, aprobada en 1924 en la Quinta Asamblea de la Sociedad de Naciones, donde se establecen los derechos de los niños y niñas:

4. FAZZIO, Adriana y SOKOLOVSKY, Jorge. Cuestiones de la Niñez (Aportes para la formulación de Políticas Públicas) 2006, Ed. Espacio. Argentina. pp.10 y ss. 
- Disponer de medios para su desarrollo material, moral y espiritual,

- Asistencia especial cuando están hambrientos, enfermos, discapacitados o han quedado huérfanos,

- Ser los primeros en recibir socorro cuando se encuentran (sic) ¿están? en dificultades,

- Libertad contra la explotación económica,

- Una crianza que les inculque un sentimiento de responsabilidad social. ${ }^{5}$

En 1948, la Asamblea General de Naciones Unidas aprobó una versión ligeramente ampliada del texto, y pasó a adoptar una nueva declaración que incluye los principios básicos de protección y bienestar de los niños: artículo 25 apartado 2. La maternidad y la infancia tienen derecho a cuidados y asistencia especiales. Todos los niños, nacidos de matrimonio o fuera de matrimonio, tienen derecho a igual protección social." ${ }^{6}$ En 1959 se adoptó una nueva declaración de diez (10) principios sobre protección y bienestar de los niños, que fue el inicio de las posteriores iniciativas. La Convención Internacional sobre los Derechos de los Niños, (CDN) es el tratado internacional más aceptado en la historia de la humanidad (pero no el más cumplido), y ha sido ratificado por todos los países, con excepción de Estados Unidos de Norteamérica y Somalia. Proclamado por la Asamblea General de las Naciones Unidas, aprobado y abierto a firma y ratificación por la Asamblea General el 20 de noviembre de 1959, en 1979, en la primera celebración del Año Internacional del Niño, la Comisión de Derechos Humanos de Naciones Unidas examinó la propuesta de Polonia y crea un grupo de trabajo encargado de revisarla y presentar un texto final. Esta declaración, después de ser aprobada en 1989, entra en vigor el 2 de septiembre de 1990. Resumimos los diez principios rectores de esta declaración.

\section{PRINCIPIOS RECTORES DE PROTECCIÓN A LA INFANCIA.?}

1. El niño disfrutará de todos los derechos enunciados en esta Declaración. Estos derechos serán reconocidos a todos los niños [...] (derecho a la igualdad).

2. El niño gozará de una protección especial y dispondrá de oportunidades y servicios, dispensado todo ello por la ley y por otros medios, [...] se atenderá siempre el interés superior del niño.

3. El niño tiene derecho desde su nacimiento a un nombre y a una nacionalidad (derecho a la identidad).

4. El niño debe gozar de los beneficios de la seguridad social [...], con este fin deberán proporcionarse, tanto a él como a su madre, cuidados especiales [...], (reconocimiento de la vulnerabilidad del menor).

\footnotetext{
5. LOS PROTOCOLOS FACULTATIVOS DE LA CONVENCIÓN. La evolución de las normas internacionales sobre derechos de la infancia.

http://www.unicef.org/spanish/rightsite/sowc/pdfs/panels/SOWC\%2oall\%2opanels\%2oSP.pdf. Consultada el 30 de abril de 2013. 6. DECLARACIÓN UNIVERSAL DE DERECHOS HUMANOS. 10 de diciembre de 1948. https://www.agpd.es/portalwebAGPD/ canaldocumentacion/legislacion/organismos_internacionales/naciones_unidas/common/pdfs/D.1-cp--DECLARACIONUNIVERSAL-DE-DERECHOS-HUMANOS.pdf. Consultada el 10 de abril de 2013.

7. DECLARACIÓN DE LOS DERECHOS DE LOS NIÑOS DE 1959. http://www.pequelandia.org/derechos/declaracion/. Consultada el 10 de abril de 2013.
} 
5. El niño física o mentalmente impedido o que sufra algún impedimento social debe recibir el tratamiento, la educación y el cuidado especiales que requiere su caso particular (Derecho a la solidaridad al menor).

6. El niño, para el pleno y armonioso desarrollo de su personalidad, necesita amor y comprensión, [...] La sociedad y las autoridades públicas tendrán la obligación de cuidar especialmente a los niños sin familia, o que carezcan de medios adecuados de subsistencia [...] (derecho al amor fraternal).

7. El niño tiene derecho a recibir educación, que será gratuita y obligatoria por lo menos en las etapas elementales [...]. El interés superior del niño debe ser el principio rector de quienes tienen la responsabilidad de su educación y orientación (derecho a ser niño educado).

8. El niño debe, en todas las circunstancias, figurar entre los primeros que reciban protección y socorro (Interés superior del menor).

9. El niño debe ser protegido contra toda forma de abandono, crueldad y explotación. No será objeto de ningún tipo de trata. No deberá permitirse al niño trabajar antes de una edad mínima adecuada [...], (derecho a la no explotación).

10. El niño debe ser protegido contra las prácticas que puedan fomentar la discriminación racial, religiosa o de cualquier otra índole [...], (Derecho a la no discriminación).

Principios que hasta la presente fecha no se han cumplido totalmente en todos los países que aceptaron, firmaron y ratificaron este convenio. Presentándose mayor incumplimiento en los países subdesarrollados. En México, a pesar que reconoció estos derechos formalmente, no se han cumplido íntegramente: Muchos menores de catorce (14) años en todo el territorio nacional trabajan, vagan o mendigan ante la indiferencia de las autoridades y de la sociedad; el trabajo infantil en los mercados, supermercados, en el campo, y otras industrias peligrosas, se permiten sin supervisión adecuada, y al respecto hay una total falta de legislación que impida la explotación infantil. En su empleo no se tienen en cuenta las necesidades especiales que requiere su condición de menor, ni siquiera a quienes de alguna forma tienen capacidades diferentes. En México no todos los niños son amados por sus padres o su familiares, sin que esto preocupe mucho a la sociedad o al gobierno de turno; algunos menores tan solo son utilizados para spot announcements, entiéndase publicitarios televisivos de comerciantes y políticos, queriendo transmitir una imagen falsa de paternalismos irreal, hipócrita y denigrante.

Los derechos fundamentales de muchos menores son violados por sus mismos padres, por las autoridades, por los empresarios que los utilizan y no les pagan el salario mínimo, los someten a jornadas similares o mayores a los adultos, y los obligan a la mendicidad encubierta. Los menores deben conformarse con tener la oportunidad de trabajar para las grandes y medianas empresas nacionales e internacionales, tan solo con las "propinas", "limosnas" (o parte de ellas) ante la complacencia y tal vez la complicidad de las autoridades. ${ }^{8}$

8. Cfr. SOLÍS QUIROGA, Héctor. Derechos del Menor de Edad. México. Biblioteca Jurídica Virtual, UNAM. http://www.juridicas. unam.mx/publica/librev/rev/facdermx/cont/166/dtr/dtr12.pdf. Consultada el 30 de marzo de 2013. 
Como ya lo expresamos no fue sino hasta 1989, cuando la Asamblea General de Naciones Unidas en la Convención sobre los Derechos del Niño, aprobó sus derechos fundamentales, que han sido ratificados por casi todos los países miembros, con dos excepciones: Somalia, que por razones políticas internas y externas no ha podido ratificarlas, y la más significativa, la del Imperio, los Estados Unidos de Norte América. Quizá este mensaje de la nación más poderosa del mundo sea un indicio para insinuar a los demás países el no cumplimiento de lo acordado, proliferando el nulo respeto de los derechos de los niños pobres, de las familias pobres y de los países pobres. Donde un buen número de menores no poseen acceso a la salud, la educación, el esparcimiento, y la protección y garantía a la libre expresión de sus opiniones, así como a un salario digno y remunerado y a un trabajo bien pago.

Todos los niños necesitan que los cuiden, los alimenten y les den cariño, una casa digna, una nacionalidad, un nombre que los distinga de los demás, descansar, divertirse sanamente, decir lo que piensan, lo que sienten, lo que les preocupa, recibir educación, hacer amistades con otros niños, hablar un idioma (al menos el natural), tener costumbres propias del grupo social y practicar la religión de sus padres; si es discapacitado recibir educación y cuidados especiales, no ser maltratado en su cuerpo ni en sus sentimientos. Todo esto dentro del núcleo familiar, y si no fuere posible, el Estado está obligado a sustituir a la familia, y en tal obligación deben comprometerse todos los gobiernos pobres y ricos del mundo. Si tiene la necesidad de trabajar, se le tienen que pagar salarios y prestaciones.

\section{EL FONDO DE NACIONES UNIDAS PARA LA INFANCIA (UNICEF) CONTRA LA EXPLOTACIÓN LABORAL INFANTIL}

La Asamblea General de Naciones Unidas ha confiado al Fondo de Naciones Unidas para la Infancia (UNICEF) la promoción de la protección de los derechos del niño, procurando que se satisfagan sus necesidades básicas, aumentar las oportunidades para que alcancen plenamente sus potencialidades. Buscando conseguir que esos derechos se conviertan en principios éticos perdurables, y normas internacionales de conducta hacia los niños, que se conviertan en realidades y no queden tan solo en hipótesis legales. Reiteramos que la supervivencia, la protección y el desarrollo de los niños son imperativos de carácter universal y forman parte integrante del progreso de la humanidad. La UNICEF ha estableciendo los siguientes ejes de acción.

1. Movilizar la voluntad política y los recursos materiales para ayudar a los países, en particular a los que están en desarrollo, a garantizar que los niños tengan derecho prioritario sobre los recursos, y a crear la capacidad de establecer políticas apropiadas y ofrecer servicios para los niños y sus familias.

2. Garantizar que se dé protección especial a los niños más desfavorecidos: víctimas de guerra, desastres, extrema pobreza, librarlos de todas las formas de violencia y explotación.

3. Responder en las emergencias, protegiendo los derechos de los niños. En coordinación con los asociados de Naciones Unidas y los organismos humanitarios. La UNICEF pone a disposición sus conocimientos y ayuda a las entidades que colaboran con servicios singulares de respuesta rápida, para aliviar el sufrimiento de los niños y de las personas responsables de su cuidado. 
4. Actividad no discriminatoria; en todo lo que se hace, tienen prioridad los niños más desfavorecidos y los países más necesitados.

5. Promover la igualdad de derechos de la mujer, de los menores y apoyar su plena participación en el desarrollo político, social y económico de sus comunidades. ${ }^{?}$

La Convención sobre los Derechos del Niño fue el primer instrumento internacional jurídicamente vinculante, que incorpora los derechos humanos básicos de los menores como: el derecho a la supervivencia, al desarrollo pleno, a la protección contra influencias peligrosas, contra los malos tratos y la explotación, la participación en la vida familiar, cultural y social que deben disfrutar los niños y niñas en todas partes. Estableciendo cuatro principios fundamentales:

1. La no discriminación.

2. El derecho a la vida.

3.El derecho a la supervivencia y desarrollo, el respeto por los puntos de vista del niño.

4. El interés superior del niño..

Todos los derechos que se establecen en la convención son inherentes a la dignidad humana y el desarrollo armonioso de todos los niños, estipulando las pautas en materia de atención a la salud, la educación y la prestación de servicios jurídicos, civiles y sociales. Los gobiernos nacionales se comprometieron a proteger y asegurar los derechos de la infancia en sus respectivos países, aceptando su responsabilidad ante la comunidad internacional cuando no cumplan con esta obligación. Los Estados parte se obligaron al firmar y ratificar la convención, para establecer leyes y todas las medidas necesarias para proteger el interés superior del menor. ${ }^{10}$

\section{RATIFICACIÓN DE MÉXICO DE LA CONVENCIÓN DE LOS DERECHOS DEL NIÑO}

Nuestro país ratificó la Convención sobre los Derechos del Niño el 21 de septiembre de 1990, aceptando los cuatro principios rectores de esta:

1. La no discriminación.

2. El interés superior del niño.

3. El derecho a la vida, supervivencia y desarrollo.

4. La opinión del niño.

En consecuencia jurídica nuestro país se comprometió a respetar y cuidar de los menores, garantizándoles por lo menos los siguientes derechos a los niños y niñas mexicanos:

9. FONDO DE LAS NACIONES UNIDAS PARA LA INFANCIA (UNICEFF) http://www.cinu.org.mx/onu/estructura/mexico/fond/ unicef.htm. Consultada el 8 de abril de 2013.

10. RATIFICACIÓN DE MÉXICO de la Convención sobre los derechos del niño.

http://www.unicef.org/spanish/crc/http://www.unicef.org/spanish/crc/. Consultada el 8 de abril de 2013. 
- Vivir en una familia que los cuide, los alimente y les dé cariño,

- Tener una casa,

- Expresarse con respeto, sobre lo que piensan, lo que sienten y lo que les preocupa,

- Tener una nacionalidad,

- Ir a la escuela y recibir educación,

- Tener un nombre y un apellido que lo distinga de los demás,

- Hablar el idioma natural, garantizar sus costumbres y practicar la religión de sus padres,

- Descansar, jugar y divertirse sanamente,

- Tener derecho a recibir una educación y cuidados especiales, si es discapacitado,

- Hacer amistades con otras niñas y niños,

- Nadie tiene derecho a maltratar su cuerpo y sus sentimientos. ${ }^{11}$

\section{EL TRABAJO DEL MENOR A LO LARGO DE LA HISTORIA}

El trabajo de los menores no es cosa nueva, todos los pueblos del mundo, hasta los más cultos y poderosos (no obstante se presenta más en los países pobres) lo han fomentado. Recordemos a los niños explotados en las minas de carbón en Inglaterra e Irlanda durante la Revolución Industrial. El abuso y aprovechamiento de los niños indígenas por los conquistadores españoles durante los 300 años del virreinato, empleando al menor para explotar las minas de plata y oro, cuyos tesoros se enviaban a la corona española, posteriormente los utilizaron en las tareas más duras e ingratas en el medio rural, comercial, de servicios y de manufactura. ${ }^{12}$

En el siglo XVIII los propietarios de las fábricas de algodón en Europa recogían o compraban a niños de los orfanatos, haciéndoles trabajar a cambio de su mantenimiento, en algunos casos niños de cinco y seis años llegaban a trabajar entre 13 y 16 horas al día: ${ }^{13}$ de modo que con la complicidad de líderes políticos, sociales y religiosos hacían trabajar a los menores en tareas tan peligrosas como los químicos. A finales del siglo XX y principios del presente siglo el problema de la explotación infantil sigue siendo muy grave, una serie de estudios realizados en 2009, mostraron que hay más de 80 millones de niños menores de 12 años que desempeñan multitud de trabajos en condiciones infrahumanas; la mayoría viven en países de América Latina, (México) África y Asia, sus condiciones de vida son pésimas y sus posibilidades de alfabetización casi nulas, sus escasos ingresos -jno salarios!- son imprescindibles para la supervivencia de sus familias y les alcanza tan solo para satisfacer las necesidades más urgentes de alimentación, vivienda y ropa. ${ }^{14}$

El trabajo de los menores ha sido un sistema de producción similar al de la esclavitud, tolerado y admitido por diversas sociedades de muchos países (pobres y ricos.), según señala un informe elaborado por la Confederación Sindical Internacional (CSI), la central obrera más grande del mundo, que representa a 166 millones de trabajadores afiliados en 309 organizaciones de 156 países. ${ }^{15}$

11. DERECHOS Y OBLIGACIONES DE LOS NIÑOS Y LAS NIÑAS.

http://www.cedhj.org.mx/derechos_humanos/cuales_son/ni\%Fios.html.Consultada el 15 de marzo de 2013.

12. LA EXPLOTACIÓN INFANTIL EN MÉXICO. En "Diario el Siglo de Torreón".

Com.mx.http://www.elsiglodetorreon.com.mx/noticia/440062.la-explotacion-infantil-en-mexico.html. Consultada el 4 de abril de 2013.

13. BIBLIOTECA DE CONSULTA Microsoft ${ }^{\circledast}$ Encarta $^{\circledast}$ 2003. (1993-2002 Microsoft Corporation. Reservados todos los derechos. 14. Ibíd.

15. CRÍTICA, LA SITUACIÓN LABORAL EN MÉXICO. Las violaciones a la Ley Federal de Trabajo (LFT) Una Constante. En Diario digital "la jornada" del once de febrero de dos mil ocho. http://www.jornada.unam.mx/2008/o2/11/index.php?section=sociedad\&a 
En nuestro país hay más de tres (3) millones y medio de niños que trabajan a causa de la pobreza y la desigualdad, para comprender legalmente la explotación infantil en México tenemos que partir de la definición legal de algunos conceptos básicos como: trabajador, salario, infancia, adolescencia y relaciones laborales.

\section{CONCEPTOS BÁSICOS DEL DERECHO DEL TRABAJO EN MÉXICO}

La Ley Federal del Trabajo en México establece que:

a)Las normas del trabajo tienden a conseguir el equilibrio entre los factores de la producción y la justicia social, así como propiciar el trabajo digno o decente en todas las relaciones laborales,

b)Se entiende por trabajo toda actividad humana, intelectual o material, independientemente del grado de preparación técnica requerida por cada profesión u oficio,

c)El trabajo es un derecho y un deber sociales,

d)El trabajo no es artículo de comercio, exige respeto para las libertades y dignidad de quien lo presta, y debe efectuarse en condiciones que aseguren la vida, la salud y un nivel económico decoroso para el trabajador y su familia, ${ }^{16}$

e)Por patrón se comprende a: "la persona física o moral que utiliza los servicios de uno o varios trabajadores", ${ }^{17}$

f)Por relación de trabajo debemos entender: "cualquiera que sea el acto que le dé origen”,

g)Trabajador es la persona física que presta a otra, física o moral, un trabajo personal subordinado,"18

h)Por trabajo personal se considera a la prestación de un trabajo personal subordinado a una persona, mediante el pago de un salario, que debe ser suficiente para satisfacer las necesidades normales de un jefe de familia", ${ }^{19}$

i)Salario es la retribución que debe pagar el patrón al trabajador por su trabajo,

j)Son niñas y niños las personas de hasta doce (12) años incompletos, y adolescentes los que tienen entre doce (12) años cumplidos y dieciocho (18) años.

rticle=042nisoc. Consultada el 20 marzo de 2013 .

16. Vid. Artículo 5․ De la Ley Federal del Trabajo. op. cit. p. 3.

Ibíd. p.5.

17. Vid. Artículo 10. Ibíd. p.8.

18. Vid. Artículo 8․ ibíd. p. 7.

19. Vid. DERECHOS Y OBLIGACIONES DEL NIÑO. Artículo 2o, op. cit. p. 4. 
El trabajador es la persona física, menor o adulta que presta un servicio subordinado, a otra persona física o moral que produce o presta un servicio; por esta actividad debe recibir un salario retributivo, que sea suficiente para alimentar a una familia y además recibir las prestaciones laborales como: seguro social, días de descanso, vacaciones, aguinaldo, reparto de utilidades etc., si alguien necesita del trabajo de un menor, también debe pagarle un salario que en ningún caso y por ningún motivo debe ser menor al salario mínimo o al salario que reciba un adulto por el mismo trabajo. Los mexicanos debemos reconocer que la fijación del salario mínimo por la Comisión Nacional de Salarios Mínimos, es una simulación, ya que el salario fijado cada año por estas autoridades laborales, no representa la característica de remunerativo que exige la constitución, la cual estipula que el salario que perciba un trabajador debe alcanzar para satisfacer las necesidades económicas de un jefe de familia, en la alimentación, vestido, salud y esparcimiento. El salario mínimo que se fija en México es por regiones, siendo la más cara la del Distrito Federal; el Consejo de Representantes de la Comisión Nacional de los Salarios Mínimos acordó otorgar un aumento general a los salarios mínimos, de las dos áreas geográficas, para el 2013 de 3.9 por ciento. Los nuevos salarios mínimos legales que rigen a partir del primero de enero de 2013 son los siguientes: área geográfica "A", 64.76 pesos diarios; área geográfica "B", 61.38 pesos diarios ${ }^{20}$.

Esto equivale a escasos seis dólares diarios por ocho horas de trabajo.

Si un trabajador adulto debe recibir por ley por lo menos un salario mínimo, y si no se lo pagan, esta conducta constituye un delito en términos del artículo 1004 de la Ley Federal del Trabajo, además de tener que recibir todas las prestaciones salariales, cuando el trabajador es menor de edad; por tanto el incumplimiento de todo ello, con mayor razón debe constituir una conducta delictiva agravada. La Ley para la Protección de los Derechos de Niñas, Niños y Adolescentes de México establece: "que son niñas y niños las personas de hasta 12 años incompletos, y adolescentes los que tienen entre 12 años y 18 años. ${ }^{21}$ La convención no hace ninguna distinción, y establece que son niños los menores de 18 años, y si realizan un trabajo subordinado deben recibir las mismas o mejores prestaciones que un trabajador adulto, (por su condición de menor.)

Sin embargo muchos menores que prestan un trabajo subordinado no reciben ningún sueldo, o reciben menos del salario mínimo, o menos de lo que se pagaría a un trabajador adulto por realizar el mismo trabajo, y tampoco reciben ninguna de las demás prestaciones laborales. Tan solo tienen que conformarse con las dádivas (propinas) de los clientes de la empresas o del patrón particular. Vemos a menores trabajando en supermercados, industria de la construcción, el campo, las minas, basureros, en las calles, sin que reciban sueldos ni prestaciones, lo que constituye una verdadera explotación laboral y violación a los derechos fundamentales de los menores trabajadores, quebrantando lo preceptuado en leyes nacionales y en la Convención Internacional sobre los Derechos del Niño, aun cuando sus gobiernos se comprometieron a velar por su protección según lo preceptuado en el artículo 32 de la Convención establece, en donde dice que:

20. NUEVOS SALARIOS MÍNIMOS 2013, Por Área Geográfica Generales y Profesionales. http://www.conasami.gob.mx/nvos_ sal_2013.html. Consultada el 12 de abril de 2013.

21. Vid. Artículo 2ㅜ. Ley para la Protección de los Derechos de Niñas, Niños y Adolescentes Cámara de Diputados del H. Congreso de la Unión, México. Secretaría General, Secretaría de Servicios Parlamentarios, Centro de Documentación, Información y Análisis. p. 1. 
"Los Estados firmantes reconocen el derecho del niño a estar protegido contra la explotación económica y contra el desempeño de cualquier trabajo que pueda ser peligroso o entorpezca su educación, o que sea nocivo para la salud o para su desarrollo físico, mental, espiritual, moral o social". Asi como: "Los Estados partes adoptarán medidas legislativas, administrativas, sociales y educacionales para garantizar la aplicación del presente artículo." 22

En la convención todos los Estados partes se comprometieron a combatir la explotación infantil, implementado todos los medios materiales y formales para evitarla: se debe impedir que el menor se enfrente a trabajos no pagados, más aun, impedir que trabaje más de seis horas, y se le pague el mismo salario que a un adulto, o bien que no se le entreguen las prestaciones sociales. Solo impidiendo la explotación infantil en cualquiera de sus formas se cumple con los compromisos internacionales, el Estado está obligado a tomar las medidas legislativas que permitan la protección de los derechos humanos de los menores trabajadores. Si las leyes administrativas, laborales, y políticas públicas no son suficientes para evitar la explotación del menor, entonces hay que solicitar la intervención de la última razón de Estado para evitarlo, y así el derecho penal debe intervenir tipificando esta conducta de explotación laboral de menores que son utilizados como empleados normales, y no se les paga un salario mínimo o se les paga un salario menor al mínimo, o al que recibe un adulto por el mismo trabajo, lo cual como ya se especificó es considerado delito.

\section{EL TRABAJO INFANTIL EN MÉXICO}

Se abarca en toda la gama tan amplia de concepciones, aceptaciones y rechazos al trabajo infantil, provocando confusiones, ya que existen desde aquellas que lo definen como un proceso favorecedor para la socialización de niños y niñas, porque fomenta la cooperación y solidaridad, y provee de destrezas, habilidades y experiencias para su futuro, hasta las opiniones que consideran que el trabajo infantil está fuera de las permisiones legales y constituye una grave violación a los derechos humanos del menor, que le impiden su desarrollo normal (biopsico-social), arrastrándolo al atraso y la pobreza de por vida ${ }^{23}$, principalmente cuando se abusa del trabajo de menores de doce años, donde regularmente se presenta la explotación infantil, prohibida por las leyes de los países que firmaron la convención del menor, sin embargo en algunos de éstos se hace muy poco para combatir la explotación laboral infantil.

Es muy preocupante la realidad mexicana en lo concerniente al abuso del trabajo infantil, pues se calcula que más de tres millones de menores - hombres y mujeres - tienen necesidad de laborar para ayudar a su familia a conseguir los alimentos necesarios para sobrevivir. Las edades de los menores trabajadores fluctúan entre los 6 y los 12 años, y luego sigue otro rango que comprende hasta los 18 años, de modo que uno de cada seis niños y niñas trabajan. En las comunidades indígenas las cifras se duplican, el 36\% de los niños y niñas trabajan sin sueldo y sin prestaciones laborales, lo que debiera constituir un delito en los términos de la legislación laboral. ${ }^{24}$

22. NORMAS QUE REGULAN EL TRABAJO DE MENORES.

http://www.problemaslaborales.com.ar/menores.htm. Consultada el 12 de abril de 2013.

23. Cfr. Becerra Millán, Abigail. Trabajo infantil en México. México 2005, Reporte temático, número 4. Centro de Estudios Sociales y de Opinión Pública., Cámara de Diputados, p. 2. Y Brom, Diego, Gutiérrez, Libertad y Puente, Bernardo. Conceptos básicos sobre trabajo infantil y trabajo infantil doméstico, Asunción Paraguay, 2004, Oficina Internacional del Trabajo, pp. 12-13.

24. El Drama Del Trabajo Infantil En México. En "Artículo Z".

http://www.articuloz.com/noticias-y-sociedad-articulos/el-drama-del-trabajo-infantil-en-mexico-424573. Consultado el 25 de marzo de 2013. 
La previsión constitucional y legal mexicana que prohíbe la utilización del trabajo infantil en menores de 12 años, fuera del núcleo familiar, ${ }^{25}$ es constantemente violada ante la complacencia de las autoridades, las empresas y los particulares que se benefician del trabajo del menor, quienes no son sancionados, aun cuando someten a los menores a jornadas laborales que exceden el máximo permitido, inclusive por la ley laboral mexicana para los adultos. La ley prevé que la jornada laboral para los menores de 14 años será menor a la de los adultos (de seis horas diarias), que no deben prestar sus servicios en lugares insalubres, peligrosos, nocturnos, en donde se expiden bebidas alcohólicas. ${ }^{26}$ En México muchos menores trabajan en lugares prohibidos, con edades no autorizadas, con jornadas superiores a la de los adultos, se utiliza a los menores por considerarlos trabajadores baratos o gratuitos, que se conforman tan solo con dádivas.

Las entidades federativas mexicanas con mayor incidencia de trabajo infantil violatorio de derechos humanos son: Chiapas, Campeche, Puebla y Veracruz, en donde la tasa de trabajo infantil oscila entre el 29 y $22.4 \%$ de la población, y las edades de los niños trabajadores son entre 6 y 14 años. En contraste, los Estados de Chihuahua, Nuevo León, Baja California y Coahuila, tienen las menores tasas de ocupación infantil, entre el 6.7 y $8.3 \%{ }^{27}$ Mención aparte es el Distrito Federal donde las cifras se confunden, pero todos ocupan, o mejor dicho utilizan en mayor o menor medida a los menores, quienes se enfrentan a una dura realidad. En el campo o en la ciudad, muchos de ellos son jornaleros agrícolas, ayudantes en pequeños talleres o maquilas, aprendices de albañiles, las niñas hacen labor doméstica en las cocinas de las fondas, cuidando otros niños, apenas un poco menores que ellas, los niños trabajan de cargadores de bultos en las centrales de abastos, dependientes de bares, "franeleros", ayudantes en los camiones recolectores de basura, y en los auto servicios de "cerillos" ("embolsadores" de mercancías). Sin que hayan sido contratados abierta y legalmente, son utilizados con una excusa que resulta vergonzosa e infantil: "Se les ayuda para su educación", con discursos tan amplios que no permiten determinar cuándo la utilización abusiva del menor constituye una conducta ilícita tipificada por la ley penal, o se necesita que se tipifique para sancionarla, originando muchas opiniones irritadas, lo cual entre otras cosas se expone de forma desesperada así:

Algunos centros de trabajo donde laboran los menores son clandestinos, y otros aprovechan su fuerza de trabajo clandestinamente, los patrones evaden su responsabilidad de pagar un salario e inscribirlos a instituciones como el Instituto Mexicano del Seguro Social (IMSS), o el Instituto del Fondo Nacional para la Vivienda de los Trabajadores (INFONAVIT) etc., pero casi todos los menores son sometidos a las formas agotadoras y denigrantes de trabajo, que repercute en su desarrollo psico-físico-social. Así la frase trillada de que: "los niños son el futuro de México y el mundo" resulta irónica ${ }^{28}$.

Por ley la jornada laboral máxima para un menor debe ser de seis horas diarias, en periodos de $2 \frac{1}{2}$ horas, y por $1 / 2$ de descanso por cada periodo; ${ }^{29}$ sin embargo en estos trabajos los menores que viven en pobreza extrema trabajan más de 40 horas semanales, sin goce de sueldo, sin prestaciones, sin descanso, ¡tan solo propinas!, o un salario inferior al mínimo, o un salario menor al que recibe un adulto por el mismo trabajo. Conducta tipificada como delito

25. Vid. Artículo 123 Constitución Política de los Estados Unidos Mexicanos. op.cit., p. 50. 26. Vid. Artículos 173-180, de la Ley Federal del Trabajo, op. cit. pp. 45-48.

27. México en cifras. Inegi http://www.inegi.org.mx/sistemas/mexicocifras/. Consultada el 25 de marzo de 2013.

28. Becerra Millán, Abigail. Trabajo infantil en México, op. cit. p.40. (las cursivas son mías) Ibíd. p. 40

29. Vid. Artículo 177 de la Ley Federal del Trabajo, op. cit., p. 45. 
según lo previsto por el artículo 1004 de Ley Federal del Trabajo, cuya tipicidad se actualiza si se comete en contra de un trabajador adulto, pero cuando se trata de menores la ley es omisa; este abuso laboral constituye una grave violación a los derechos fundamentales de la niñez (vivir la infancia). En opinión de algunos autores la incapacidad de México para atender la regulación del trabajo infantil deriva de tres grandes problemas:

1. La incapacidad del gobierno y el Estado para hacer cumplir la ley en materia de trabajo infantil.

2. La falta de compromisos serios en cuanto a las políticas públicas y de gasto asignado al cumplimiento de los derechos de la niñez.

3. La carencia de un marco jurídico que permita la reforma de las instituciones públicas encargadas de velar por el cumplimiento de los derechos recogidos en el mismo marco legal..$^{30}$

En una de las últimas reformas estructurales en México, en materia laboral, apenas entrada en vigor el primero de diciembre de $2012,{ }^{31}$ tampoco se pudo o se quiso regular y sancionar el abuso del trabajo infantil en México, cuando se utiliza a los menores entre seis y catorce años de edad, y no se les paga el salario mínimo ni las prestaciones laborales. Limitándose únicamente a prohibir las labores de las mujeres embarazadas o en periodos de lactancia, y de los menores de 16 años, cuando exista una contingencia sanitaria, sin perjuicio en sus salarios, derechos y prestaciones. Pero de los menores trabajadores, y encubietto en una falsa acción altruista de las empresas, fundada en el hecho de solidaridad con el menor trabajador ${ }^{32}$, consistente en "ayudarlo en sus estudios", se aprovechan de su fuerza laboral y no les pagan el salario mínimo. Este abuso quedó sin ser reconocido en su perjuicio, sin sanción laboral y menos penal.

\section{LA DEMANDA POR EL TRABAJO INFANTIL}

Los empleadores recurren a la mano de obra infantil por muy diversas razones, entre otras, por su menor costo y supuesta destreza en algunas labores, ${ }^{33}$ siguiendo la falsa creencia de que los niños poseen ciertas características físicas exclusivas que los hacen más hábiles para algunos trabajos, como tener dedos pequeños que los hacen diestros en los trabajos textiles, y para confeccionar alfombras, coser prendas de cuero y piel, manufacturar complementos deportivos, fabricar vidrio y cristal, cierres, etc.; se tiene la creencia falsa de que lo hacen mejor y más rápido. Ya se ha comprobado que no siempre es así, pues casi todas las tareas que efectúan preferentemente los niños, las pueden hacer los adultos con la misma destreza. Lo que sí es una realidad, es que por su condición física inferior a la de los adultos, los niños deben ejecutar tareas que requieran poca fuerza física y escaso desgaste emocional. ${ }^{34}$ Los niños no son en realidad económicamente necesarios para la industria manufacturera, de servicios o cualquier otra, ellos deben realizar actividades que favorezcan su desarrollo físico y psicológico. Es muy

30. Becerra Millán, Abigail. Trabajo infantil en México, op. cit. p.40 y 41.

31. Vid. Reforma laboral 2012, México. http://reformalaboralmexico.com/descarga-analisis/. Consultada el 2 de abril de 2013.

32. Publican reforma laboral. En idconline; Tras su aprobación en el Congreso, y la firma del decreto respectivo por el Ejecutivo federal, la nueva norma entrará en vigor el 1 de diciembre. http://www.idconline.com.mx/laboral/2012/11/30/publican-reformalaboral. Consultada el quince de abril de 2013.

33. Manel Costas, Joan. Vidas explotadas, (la explotación infantil); México. 2008, Ediciones Formación Intervidas, pp. 20 y ss. 34. R. Anker y s. Barge: Is Child Labour Really Necessary in India's Carpet Industry. Coloquio Celebrado en la India del 26 al 28 de julio de 1995, publicación al respecto por la OIT. Ginebra, 2006, pp. 12-18. 
cuestionable que algún sector productivo o de servicios necesite a los niños como trabajadores por, presuntamente, ser altamente competitivos con los adultos.

La pobreza es sin duda la causa principal del trabajo infantil, muchos niños trabajan para ayudar a su familia, y evitar constituirse así en una carga familiar; sin embargo, paradójicamente, el trabajo infantil no hace otra cosa que generar más pobreza. ${ }^{35} \mathrm{Si}$ bien la pobreza no es la única causa que explica la utilización del trabajo infantil, sí es la más profunda, y otros factores son: la falta de oportunidades de educación y cultura. El sistema educativo mexicano es deficiente, de baja inversión por los gobiernos -federal y estatales-, con sistemas de transmisión de conocimientos, y ejercicio del juicio crítico anacrónicos, de mala calidad, con escasez de infraestructura, planes de estudios inadecuados, con una "disciplina" violenta y una insuficiente preparación de los maestros, lo que hace poco atractiva la escuela para los menores como sistema formativo, quedando entonces el trabajo como una alternativa de vida cotidiana. ${ }^{36}$ Esperamos los mexicanos que las recientes reformas constitucionales en materia educativa, promulgadas el 25 de febrero de 2013 en México, con la implementación de los tres grandes ejes de acción para innovar la educación, disminuyan la explotación laboral infantil. Estos cambios se agrupan en tres grandes ejes, a saber:

a) Lograr que los alumnos sean educados por mejores maestros — capacitados, responsables y cumplidos -; para lograr este fin se crea el "Servicio Profesional Docente", para que el mérito profesional sea la única forma de ingresar, permanecer y ascender como maestro, director o supervisor; que se espera proporcione certidumbre y garantía laboral,

b)La evaluación como un mecanismo eficiente para preservar y mejorar la calidad de la enseñanza, con el Instituto Nacional para la Evaluación de la Educación (INEE), con rango constitucional y autonomía. Además, se ordena la creación de un Sistema Nacional de Evaluación Educativa que tomará en cuenta las condiciones y desafíos que enfrentan los maestros en su realidad cotidiana,

c) Mejorar las condiciones para la formación integral de todos los alumnos del país, fortaleciendo la autonomía de gestión de las escuelas, y aumentando el número de escuelas de tiempo completo para brindar oportunidades educativas, culturales y de desarrollo integral para todos los estudiantes del país ${ }^{37}$.

Mientras estos cambios se cristalizan en México, observamos que paradójicamente el $85 \%$ de los países en desarrollo tienen establecido en su legislación que la educación es obligatoria, al menos la básica, ${ }^{38}$ y sin embargo es en estos lugares donde menos se tiene acceso a esta educación elemental. Los menores y los adultos mayores regularmente trabajan en el sector informal, desempeñando tareas tan poco atractivas para los adultos en plenitud. Esta es la verdadera realidad de la demanda del trabajo infantil, utilizados en trabajos poco o nada remunerados, en labores que los adultos no desean hacer, sin salarios, sin prestaciones, sin seguridad social, y sin que este abuso este tipificado como delito. Si el no pagarle a un adulto

35. Ibíd. p. 27.

36. Cfr. Ornelas, Carlos. Sistema Educativo Mexicano. (La transición de fin de siglo) México 1995, Fondo de Cultura Económica, p. 45 y ss.

37. Peña Nieto, Enrique. La Reforma Constitucional El Estado Mexicano. http://www.presidencia.gob.mx/articulos-prensa/ con-la-reforma-constitucional-el-estado-mexicano-asume-plenamente-la-accion-rectora-y-reguladora-de-la-educacion-epn/. Consultada el 26 de marzo de 2013.

38. Vid. Artículo $3^{\circ}$. Constitucional, op. cit. p. 3 . 
el salario mínimo constituye un delito, con mayor razón (y con mayor sanción) debe constituir un delito, cuando no se le paga el salario mínimo a un menor, que fue utilizado abusivamente por una empresa o un patrón particular. Es conocido por muchos de nosotros que en derecho penal predomina el principio de legalidad (nullum crimen sine lege), en virtud del cual se prohíbe imponer pena alguna, por una conducta que no esté exactamente descrita en la ley, y por esta razón proponemos la tipificación de la utilización del menor cuando no se le pague el salario mínimo y demás prestaciones laborales.

\section{LA EXPLOTACIÓN LABORAL INFANTIL EN MÉXICO}

En países como México es usual que menores (desde los seis años) sean llevados por su familia a realizar trabajos en zonas rurales o urbanas, donde frecuentemente no se les paga; son considerados como "adoptados al trabajo", es decir; ayudan al trabajador adulto para que este realice más trabajos, así el patrón obtiene un beneficio adicional por el trabajo del menor no remunerado, pues solo les paga a los padres por su trabajo prestado, no así el del menor, lo que se traduce en explotación del menor, quien en ocasiones realiza un trabajo excesivo para su edad, acompañado de malos tratos: esta conducta debe ser sancionada penalmente.

La explotación infantil aumenta alarmantemente en los países pobres, en el sur de Asia un $20 \%$ hacen jornadas de 13 horas diarias por un sueldo de entre $€ 15$ y $€ 20$ euros al mes, (aproximadamente $\$ 400.00$ pesos mexicanos, según el tipo de cambio); en Latinoamérica trabajan 17 millones de niños de entre 5 y 17 años, los ingresos de estos menores suponen del 10 al 20\% del ingreso familiar; en México hay 3 millones 14 mil 800 personas de 5 a 17 años que trabajan, de los cuales $67 \%$ son niños y $33 \%$ niñas, ${ }^{39}$ a los cuales no les pagan dicho trabajo subordinado - solo reciben propinas-, o ganan menos que un adulto (algunos hasta diez veces menos, según el salario que perciba el adulto). ${ }^{40}$ Presentándose la relación inversamente proporcional: “a países más pobres, niños más explotados laboralmente." La Organización Internacional del Trabajo (OIT) declaró que: "el trabajo forzado (por la necesidad) de los menores, la esclavitud laboral y el tráfico criminal de seres humanos, en especial de mujeres y niños, están creciendo en el mundo y adoptando nuevas e insidiosas formas." ${ }^{41}$

Con la explotación a que son sometidos los niños y niñas violentan sus derechos humanos, agravadas por la circunstancia de que se trata de vidas en desarrollo, obligados por la necesidad o por sus progenitores a realizar trabajos lícitos o ilícitos como: la ayudantía, el servicio, la explotación sexual, el tráfico de drogas, su utilización en conflictos armados, explotación similar a la esclavitud personal, que se creía eliminada. La explotación infantil no tiene una solución fácil, ya que el salario de estos niños representa un importante porcentaje en la balanza de pagos de muchos países pobres.

La explotación infantil provoca muchísimas dificultades sociales y grandes desafíos para los gobiernos, agencias intergubernamentales, organizaciones no gubernamentales, por la significativa variedad de etnias y razas que hacen de cada país un contexto diferente y particular,

39. Instituto Nacional De Geografía E Informática (INEGI) http://cuentame.inegi.org.mx/poblacion/ninos.aspx?tema=P consultada el 8 de abril de 2013 .

40. La Explotación Infantil: http://www.youtube.com/watch?v=bsdKKfRp8BY[/media. Consultada el 25 de febrero de 2013.

41. Organización Internacional Del Trabajo. (OIT) http://www.ilo.org/global/lang--es/index.htm\#a1. Consultada el ocho de abril de 2013 . 
en todo lo cual México comparte esta característica. ${ }^{42}$ Las dificultades para superar la explotación infantil están relacionadas con el desarrollo histórico de cada país. En México dejó huellas socioculturales la época virreinal, que aun repercute modelando la identidad de hombres y mujeres, niños, niñas, ricos y pobres, pero más en estos últimos, tanto más persiste en actitudes autoritarias en nuestro país como: la mentalidad patriarcal, el machismo, la sumisión de la mujer y los menores a los padres, al patrón, al maestro, al gobierno, a los líderes: son condiciones que determinan el lugar de los infantes en la sociedad mexicana y latinoamericana, acentuando su explotación. Estamos ante un sistema de control y dominio profundamente arraigado en la mentalidad de la gente, en particular de los niños pobres, quienes habitualmente se consideran a manera de objetos y no seres humanos, sin derechos ni libertades. Es la posición social que se les asigna a menores degradados ante una sociedad silente, que tiende a ocultar el problema.

En México los supermercados tienen una gran demanda en la utilización de los menores de edad, utilizándolos sin remunerarlos, constituyendo así una forma de ingreso familiar. Representando beneficios económicos a firmas nacionales y trasnacionales, quienes obtienen mano de obra gratuita, con la complacencia de una buena parte de la sociedad mexicana, y el desinterés de las autoridades para aplicar la ley.

\section{CONTRA LA EXPLOTACIÓN LABORAL INFANTIL}

Es imprescindible que los niños, niñas y adolescentes, sus padres y hasta las autoridades (aunque parezca una perogrullada) de México y del mundo conozcan los derechos de los menores reconocidos en los tratados internacionales, e incluidos en la Constitución. Para que estén conscientes que utilizarlos como trabajadores y no pagarles un salario y no proporcionarles las prestaciones a las que tienen derecho, debe constituir un delito. No debemos permitir la explotación de los menores que trabajan sin ningún sueldo o con sueldos míseros, en condiciones de trabajo inadecuadas, expuestos a ambientes que atentan contra su salud, su integridad física y emocional, tenemos que desalentar la explotación laboral infantil a través de la norma penal, evitar que los menores sean manipulados por sus mismos padres o por patrones abusivos.

Teniendo presente que las penurias económicas de nuestro país dificultan combatir la explotación laboral de los menores, ya que es una necesidad su ingreso en el hogar, se tendrá en cuenta que de acuerdo a lo establecido en la convención, los menores de catorce años no deben trabajar fuera del núcleo familiar; sin embargo las penurias los obligan a trabajar. Ante esta realidad la ley laboral debe protegerlos, obligando a los patrones a pagarles por lo menos el salario mínimo, y a otorgarles las prestaciones laborales a que tienen derecho todos los trabajadores. Para el cumplimiento de esta obligación no han sido suficientes las disposiciones administrativas, por esta razón es tiempo de tipificar esta conducta como delito.

Para evitar que los patrones (personas físicas y morales) violenten lo establecido por la ley ("le den vuelta a la ley"), arguyendo que no emplean a los menores, que tan solo los están ayudando en sus gastos escolares, que les están dando la oportunidad en sus negocios de supermercados, o de las demás industrias, para obtener algunos ingresos y que por eso normalmente celebran convenios entre los gobiernos y las cámaras de industria y comercio, verbigracia el celebrado con el gobierno del Distrito Federal (DF) y la Asociación Nacional de 
Tiendas de Autoservicio y Departamentales ( $A N T A D)$, con todo lo cual proclaman protegerlos, pero en los hechos se incumple todo esto. En el acuerdo se menciona que el trabajo es un "apoyo" para que los menores continúen sus estudios. "En la Ciudad de México hay unos 9 mil menores de edad que trabajan como empacadores en tiendas de autoservicio... Carecen de salario, contrato y prestaciones, sólo reciben propinas de los clientes".... "autoridades y empresas se desentienden de su situación”,... "la Organización Internacional del Trabajo la considera un ejemplo de explotación infantil”"43.

Ante esta realidad social se debe establecer legalmente que los servicios que prestan los patrones de los supermercados, y las demás empresas como empacadores de mercancías y otras actividades, no deben ser considerados como opcionales, sino obligatorias; para evitar cerrar fuentes de empleos, es decir, todos los supermercados y cualquier otra industria o comercio, se tiene que establecer como una obligación la de empaquetar las mercancías a los clientes, o bien tener una persona que dirija el tránsito en los estacionamientos de esos lugares, tener personas que carguen los bultos, y para realizar estas actividades los patrones deben contratar personal con su contrato laboral en rigor: si un trabajador necesita que se le auxilie en su trabajo, el patrón deberá contratarlo y pagarle su salario, aun cuando este sea familiar del trabajador, de modo que tendrá que otorgarle las prestaciones de ley.

Para lograrlo se deben establecer metas con indicadores de resultados objetivos, con programas que incidan en las políticas públicas, que indiquen las fuentes reales de cumplimiento de la ley, articulando en forma dinámica los esfuerzos del gobierno y la sociedad civil. Cuidar a los menores, es muy importante, ya que se trata del futuro de la sociedad. Si se procura el establecimiento de redes de atención e intervención para evitar la explotación infantil en el territorio nacional, incentivando el desarrollo integral del menor en su familia, se logran importantes avances en la disminución de la explotación infantil, para que los menores se vinculen a las acciones conjuntas multidimensionales. Parafraseando a Faleiros: "...Estableciendo una alianza de actores y fuerzas, en un bloque de acción, al mismo tiempo político y operacional." ${ }^{44}$

Propugnamos por que los menores estén bajo la protección de la familia, y del Estado, buscando siempre lo mejor para el menor. Por otra parte también se debe buscar sancionar la explotación infantil, tipificando como delito: La utilización por los patrones de trabajos, empleo, uso o abuso subordinado del menor, y no les paguen un salario digno, o no les otorguen las prestaciones laborales, siendo delito sobre todo el hecho de no reducirles la jornada de trabajo, con sus lapsos de descanso, establecidos en la ley laboral. Que no sea causa de exclusión de responsabilidad del patrón, el hecho de que el trabajador menor de edad, está ayudando a sus padres en un trabajo subordinado, quedando prohibido además de que éstos reciban las propinas de los clientes de los patrones, cuando originariamente pertenezcan a los niños.

\section{LAS MEJORES FORMAS DE LA SUPRESIÓN DE LA EXPLOTACIÓN LABORAL INFANTIL}

43. Ramírez Cuevas. Jesús Los Niños empacadores, necesarios para el sostenimiento de Miles de Familias "Los cerillos de Wal-Mart" en: "Diario la Jornada digital". http://www.jornada.unam.mx/2005/08/07/mas-cuevas.html. Consultada el diecisiete de abril de 2013.

44. Faleiros, Vicente. Redes de Explotación y Abuso Sexual y Redes de Protección, En: Para Combatir la Violencia, (El Papel de la Familia y de la Asistencia Social en la Acción Junto a Niños y Adolescentes) Fundap, Brasil. 20oo. Ministerio de la Providencia Social. pp. 38 y. ss. 
Es conocido muy frecuentemente que los gobiernos se niegan a admitir que existan problemas en sus países sobre la explotación laboral infantil, aun cuando la realidad les demuestra que está presente. El combate a la explotación laboral infantil requiere una acción inmediata, general y constante; basada en la educación, la conciencia de la sociedad y la atención a necesidades familiares. La convención sobre los Derechos del Niño comenzó a combatir la explotación laboral infantil por medio de acuerdos globales, adoptando varias proposiciones relativas a la regulación del trabajo infantil, en el foro: "Las Peores Formas de Trabajo Infantil". Naciones Unidas reconoció que el trabajo infantil es producto en gran parte de la pobreza, y una de las soluciones a largo plazo radica en el crecimiento económico sostenido adecuado al progreso social. ${ }^{45} \mathrm{E}$ compromiso de los gobiernos de respetar, proteger y promover a la infancia, es un elemento clave en la creación de un entorno seguro para los menores.

Por ello se acordó que los gobiernos se comprometieran a crear marcos legislativos que contengan las normas políticas, jurídicas y sociales con programas internacionales que se apliquen en sus respetivos países. El informe de la OIT intensifica la lucha contra el trabajo infantil, disminuyendo en términos generales hasta un 15\%, sin embargo aumentó en un 7\% en los menores varones, el trabajo entre los jóvenes de 15 a 17 años aumentó en un 20\%, pasando de 52 a 62 millones.

El 1ro. de junio de 1999, La Conferencia General de la Organización Internacional del Trabajo consideró la necesidad de adoptar nuevos instrumentos para la prohibición y eliminación de las peores formas de trabajo infantil, determinándose lo siguiente:

1. Los miembros se comprometen a eliminar progresivamente el trabajo de los menores, procurando el desarrollo físico y mental.

2. La edad mínima para trabajar como compromiso de los Estados miembros será de quince años, y, excepcionalmente, de catorce y trece años.

3. Permanece la obligación de enviar a la escuela a los menores de quince años de edad.

4. Para los trabajos peligrosos, la edad mínima será de dieciocho años.

5. Los miembros que ratificaron este convenio, se comprometieron a proporcionar a los menores trabajadores cursos de enseñanza o formación en una escuela o institución de formación, aprobada por la autoridad competente e implementar un programa de orientación. ${ }^{46}$

De igual forma el artículo $9^{\circ}$. de la misma Convención establece las obligaciones procesales impuestas a los países parte de la convención, acordándose lo siguiente:

45. Convenio Sobre La Prohibición De Las Peores Formas De Trabajo Infantil Y La Acción Inmediata Para Su Eliminación. (Nota: Fecha de entrada en vigor: 19:11:20oo) Lugar: Ginebra, Sesión de la Conferencia: 87. Fecha de adopción: 17:06:1999 Sujeto: Eliminación del trabajo infantil y protección de los niños y de los adolescentes. Estatus: Instrumento actualizado. Este instrumento forma parte de los convenios fundamentales. La Conferencia General de la Organización Internacional del Trabajo: Convocada en Ginebra por el Consejo de Administración de la Oficina Internacional del Trabajo, y congregada en dicha ciudad el 1. o de junio de 1999, en su octogésima séptima reunión.

46. Cfr. Artículos $1^{\circ}$. $2^{\circ}$. $3^{\circ}$ y $4^{\circ}$. Del Convenio sobre la edad mínima de admisión al empleo de los menores. Instrumento actualizado como parte de los convenios fundamentales. OIT. http://www.unicef.org/mexico/spanish/mx_resources_138_OIT.pdf. Consultada el 18 de abril de 2013 . 
a) La autoridad competente deberá prever todas las medidas necesarias, incluso de sanciones apropiadas, para asegurar la aplicación efectiva de las disposiciones del presente Convenio,

b) La legislación nacional o la autoridad competente deberán designar a las personas responsables del cumplimiento de las disposiciones del presente convenio,

c) La legislación nacional o la autoridad competente determinará los registros u otros documentos que el empleador deberá llevar y tener a disposición de la autoridad competente, para verificar el cumplimiento de las obligaciones.

El Consejo de Administración de la Conferencia Internacional del Trabajo, en noviembre de 2010, aprobó el Plan de Acción Mundial para la eliminación de las peores formas de trabajo infantil, vigente hasta 2016. El Plan presenta un programa estratégico y un plan de acción para la OIT y, en particular, para el IPEC, que se aplicará durante los próximos años. ${ }^{47}$

\section{LEGALIDAD Y REALIDAD DE LOS DERECHOS HUMANOS DE LOS MENORES TRABAJADORES EN MÉXICO}

Después de reseñar la plataforma jurídica nacional e internacional sobre los derechos humanos de los niños trabajadores, cuestionamos: ¿si hay disposiciones legales que protegen al menor trabajador, por qué sigue su explotación? ¿Por qué hay tantos niños menores de 6 a 14 años trabajando como adultos? ¿Por qué hay niños, niñas y adolescentes que trabajan sin que les paguen sus salarios? ¿Por qué las autoridades mexicanas y de otros países no se esmeran en aplicar la ley?

El relator especial de derechos humanos de los migrantes de la ONU, Jorge Bustamante, en 2007 calificó de incongruente al gobierno federal mexicano por afirmar éste que México es un país de leyes, cuando miles de niños son explotados, percatándose de esta situación en su visita al municipio Ayotzinapa, en los Pinos, Culiacán Sinaloa, y en donde pudo apreciar el caso de un menor que fue atropellado en un campo de cultivo en ese municipio de Sinaloa, que era trabajador agrícola de tan solo 11 años de edad, con un salario menor al mínimo y trabajando más de la jornada laboral oficial, y ante lo cual expresó que, sin constituir un caso aislado, se trataba de que:: "La Secretaría de Gobernación (haciendo referencia al Estado mexicano) ha sido incapaz de cumplir con la ley mexicana y con los tratados internacionales que ha firmado, en los que se prohíbe el trabajo infantil"; también señaló la incongruencia que existe entre las leyes mexicanas, que prohíben el trabajo de menores de 14 años, y la manera en que el gobierno protege la violación de esas leyes, y así perjudica a los grupos más vulnerables. ${ }^{48}$

La Red por los Derechos de la Infancia en México exhortó a la Comisión de Atención a Grupos Vulnerables de la Cámara de Diputados, a debatir para "reestructurar" la iniciativa de una Ley General para la Protección de los Derechos de la Niñez, por no cumplirse el objetivo de protección a la infancia. Actualmente en México hay más de veintinueve (29) millones de niños, niñas y

47. Programa Internacional Para La Erradicación Del Trabajo Infantil (IPEC). http://www.ilo.org/ipec/lang--es/index.htm\#a1. Consultada el og de abril de 2013.

48. La Jornada De Guerrero. En México no se cumple la ley sobre el trabajo infantil: relator de la ONU.

http://www.lajornadaguerrero.com.mx/2007/o3/o7/index.php?section=sociedad\&article=006n1soc. Consultada el once de abril de dos mil trece. 
adolescentes, con cerca de tres (3) millones y medio trabajando en forma clandestina, sin pago de salario, ni con las prestaciones laborales a que obliga la Ley a los patrones; solo se conforman con "propinas" o alguna cantidad inferior al salario mínimo. Las instituciones gubernamentales no tienen la capacidad para garantizar los derechos fundamentales de los menores trabajadores, no pueden evitar el trabajo de menores de catorce (14) años, no hay mecanismos adecuados de ayuda a sus familias, no se define al órgano responsable para para hacer seguimiento a esa prohibición, y tampoco se orientan convenientemente las políticas públicas para evitar que los niños trabajen. ${ }^{49}$

En nuestro país se vulneran los derechos humanos fundamentales de los menores, ante la indiferencia de las autoridades y de la misma sociedad. El subempleo es aceptado por la necesidad de sobrevivir, sepultando las aspiraciones de millones de niños a vivir su infancia.

\section{POR LA TIPIFICACIÓN COMO DELITO, LA UTILIZACIÓN SIN SUELDO NI PRESTACIONES DEL MENOR TRABAJADOR}

Si con instrumentos administrativos y de derecho laboral no se puede evitar la explotación laboral infantil, pues millones de niños son utilizados por empresas o patrones abusivos, tenemos que considerar la intervención del derecho penal que se revela como el ordenamiento punitivo vigente en determinado lugar y tiempo, ${ }^{50}$ con sus características de: derecho público, sancionador, valorativo, finalista (en atención al fin que persigue) y personalísimo. Que contiene una sanción particularmente grave, estableciéndose que esa peculiaridad no deriva en la cantidad y calidad de sanción que se le impone a quien contraviene la prohibición u obligación establecida en la ley penal, sino en que su objetivo no se reduce a la mera acción reparadora de los daños y perjuicios causados, que establecen como objetivo principal los demás derechos, de modo que al derecho penal le importa más la prevención general y particular de la conducta antisocial que vulnera los derechos protegidos legítimamente por el Estado. La norma penal se inserta con el fin principal de impedir la comisión de nuevas violaciones de la conducta tipificada que vulnera los derechos de las personas ${ }^{51}$. La ley penal asocia la conducta a la pena, la coerción estatal tiene por objeto proveer seguridad jurídica mediante la prevención especial resocializadora, evitando conductas delictivas futuras por parte del autor. ${ }^{52}$

La seguridad jurídica es seguridad de coexistencias, la debemos entender, aceptar y buscar en su materialidad, en la posibilidad de disponer de todos los elementos necesarios para el cumplimiento de los fines, requiriéndose la certeza de la efectiva disposición de los bienes en el momento en que se requieren. Solo así provocaremos el sentimiento de seguridad jurídica que debe permear en toda la sociedad. Los menores deben sentir en esa forma la seguridad jurídica para crecer como individuos libres y apreciados por la sociedad y por su familia. Con las dos consecuencias jurídicas del derecho penal que son: toda pena presupone la culpabilidad del sujeto cuando cometió un hecho antisocial, y toda medida de seguridad presupone una continua peligrosidad del sujeto para el futuro. Así se sienta el principio punitivo de "La culpabilidad del sujeto activo es la base de la medición de la pena". Aunque falte la culpabilidad, es perfectamente posible imponer una medida de seguridad, si el sujeto, como consecuencia de su

49. Ven Riesgos En Iniciativa Para Protección De Los Derechos De La Niñez. En: Sinembargo. MX http://www.sinembargo.mx/1104-2012/203892. (11. 04. 2013).

50. Cfr. Pavón Vasconcelos, Francisco. Diccionario de Derecho Penal, México, 2003, 3a. Edición, Porrúa, p. 354.

51. Zaffaroni Eugenio, Raúl. Derecho penal, (parte general), México. vol. I, Cárdenas Editor y Distribuidor. 1988, p. 25. 52. Ibíd., p. 64. 
estado, es un riesgo para la colectividad ${ }^{53}$. La culpabilidad se presenta cuando una persona actúa por su propio derecho o en representación de una persona moral, y explota laboralmente a los menores.

Considerar como delito la utilización laboral de menores de 14 años, fuera del círculo familiar, que no perciban el salario mínimo, o perciban cantidad menor al salario mínimo asignado a los demás trabajadores, y que realicen la misma actividad, sería una medida de protección y vigilancia a favor de los menores. Con facultades a las autoridades para ordenar el pago inmediato de los salarios devengados, y no cobrados por los menores, sin que constituya ninguna quita el haber recibido los menores una gratificación (propinas) por los clientes de los empleadores, con la obligación de éstos de resarcir las diferencias salariales.

Todos los gobiernos que firmaron y ratificaron la Convención de los Derechos Humanos de los Menores, deben reconocer que se comprometieron a evitar su violación; ésta se actualiza en la explotación laboral del menor por no pagarle un salario ni las prestaciones labores, hipótesis comprendida tácitamente en cualquiera de las formas de explotación que prevé el artículo 34, de la convención: entonces se obligaron a implementar todos los mecanismos de respuesta para la preservación de los derechos del menor, entre ellos la creación, aplicación y cumplimiento de los tipos penales apropiados para proteger a los niños y sancionar a sus explotadores.

Los patrones que necesitan del trabajo de los niños y niñas, deben estar conscientes que tienen la obligación moral y legal de pagarles un salario y otorgarles las prestaciones laborales a que tienen derecho, deben tener presente el problema legal-penal al que se enfrentan si no lo hacen. Las leyes (penal y laboral) deben sancionar estas conductas y proteger los derechos humanos de los menores trabajadores. La policía, los ministerios, públicos o fiscales y jueces, deben perseguir al delito y a los delincuentes que truncan las aspiraciones laborales de los menores, que son precisamente la obtención de un salario y las prestaciones laborales.

Estamos de acuerdo que el derecho penal sólo se legitima cuando protege intereses fundamentales de la persona o de la sociedad (principio de lesividad), que interviene cuando las demás medidas disponibles del ordenamiento jurídico no resultan suficientes para la tutela del bien jurídico (principio de subsidiariedad o intervención mínima); así el interés merecedor de protección jurídico-penal deriva de la valoración por la norma de la agresión del bien jurídico protegido, y para solicitar la protección penal se debe justificar que la agresión al bien jurídico protegido ha sido la más grave, y sólo entonces puede verse la especial significación que representan los medios de reacción del derecho penal frente a los comportamientos punibles, pues inciden en manera decisiva en la persona o en sus bienes, como lo afirma Mezger: "El derecho penal conlleva los más graves ataques a la libertad, el honor, al patrimonio, incluso a la vida de los ciudadanos". ${ }^{54}$

Emplear a un menor, hacerlo trabajar jornadas iguales o mayores a las que están sometidos los adultos, trabajo que significa un beneficio económico para el patrón (empresa o persona física), y no pagarle el salario mínimo ni las prestaciones a las cuales tiene derecho de acuerdo a la ley laboral, envuelve la transgresión más grave de afectación al patrimonio físico y moral del menor, que incide en el núcleo familiar, pues los menores trabajan con la esperanza de obtener

53. Roxin, Claus. Derecho Penal. (parte general), España, Tomo I, fundamentos de la estructura de la teoría del delito, Trad. y Notas de Diego-Manuel Luzón Peña, Civitas, 1997, p. 42.

54. Cit. Mata Y Martín, Ricardo. Delincuencia Informática y Derecho Penal, Madrid, Edisofer Sl., 2001, p. 19. 
un salario que les permita desarrollarse física, mental y socialmente. Apoderarse del fruto del trabajo del menor, obligándolo a la mendicidad disfrazada de caridad pública, por ejemplo mediante "propinas", significa la agresión más grave a su libre desarrollo físico y psíquico con trascendencia a buena parte de su existencia. Este delito debe agravarse cuando el patrón les quita parte de la obtención de las dádivas de sus clientes a los menores.

Hay que quitarle a esta forma de explotación la etiqueta engañosa de que se trata de una labor de carácter voluntario de los menores, y una actitud filantrópica de los patrones, negándoles las garantías y prestaciones legales correspondientes. Ya que los ocupan como verdaderos trabajadores sin sueldo, ya que les exigen llevar uniforme, llegar a tiempo para sus turnos, y son castigados con horas extras, a trabajar en horas inconvenientes o hasta la pérdida de sus "puestos". Esto se llama "explotación laboral" y debe ser tipificado como delito.

\section{CONCLUSIONES}

1. Las grandes empresas nacionales e internacionales en México y en la gran mayoría de países pobres (aunque no están exentos los países ricos), se aprovechan de la mano de obra barata o regalada de los menores de edad.

2. Los menores de edad por su trabajo no obtienen los estándares mínimos de prestaciones legales, como: salario mínimo, seguro social y sanitario, vacaciones, aguinaldos, capacitación para el trabajo, protección a trabajos de riesgo.

3. El Fondo de Naciones Unidas para la Infancia (UNICEF) considera al trabajo de los empacadores de las tiendas de autoservicio, y otras empresas que ofrecen trabajos a menores sin sueldo ni prestaciones, una de las actividades clasificadas como de explotación infantil.

4. La UNICEF ha estableciendo la obligación de los Estados parte de movilizar la voluntad política, y los recursos eficaces para garantizar que se dé protección especial a los niños, para librarlos de todas las formas de explotación.

5. México ratificó la Convención sobre los Derechos del Niño el 21 de septiembre de 1990, aceptando los cuatro principios rectores de esta: la no discriminación, el interés superior del niño, el derecho a la vida, supervivencia (no explotación del menor), desarrollo y preferencia por la opinión del niño.

6. Por ley la jornada laboral máxima para un menor debe ser de seis horas diarias, con periodos de dos horas y media por media de descanso por cada periodo; sin embargo, los menores que viven en pobreza extrema trabajan más de 40 horas semanales, sin goce de sueldo, sin prestaciones, sin descanso, tan jsolo con propinas! o un salario inferior al mínimo, o un salario menor al que recibe un adulto por el mismo trabajo. Conductas antisociales que deben ser consideradas como delictivas.

7. En países como México es usual que menores (desde los seis años) sean llevados por su familia a realizar trabajos en zonas rurales o urbanas, donde frecuentemente no se les paga; son considerados como "adoptados al trabajo", lo que se traduce en explotación del menor, quien en ocasiones realiza un trabajo excesivo para su edad, acompañado de malos tratos; estas conductas deben ser sancionadas penalmente. 
8. Todos los gobiernos que firmaron y ratificaron la Convención de los Derechos Humanos de los Menores, se comprometieron a evitar su violación, ésta se actualiza en la explotación laboral del menor cuando se le emplea y no se le paga un salario ni las prestaciones labores. Surge para ellos la obligación de implementar todos los mecanismos de respuesta para la preservación de los derechos del menor, incluyendo la penal; con la creación, aplicación y cumplimiento de los tipos penales para proteger a los niños de la explotación, en cada país parte. Entre ellos nuestro país.

\section{BIBLIOGRAFÍA}

- ANKER Y S. BARGE: Is Child Labour Really Necessary in India's Carpet Industry. Coloquio Celebrado en la India del 26 al 28 de julio de 1995, Ginebra, 2006. Publicación al respecto por la OIT.

- BeCERRA MiLlán, Abigail. Trabajo infantil en México. México 2005, Reporte temático, número 4. Centro de Estudios Sociales y de Opinión Pública., Cámara de Diputados.

- BROM, Diego, GUTIÉRREZ, Libertad y PUENTE, Bernardo. Conceptos básicos sobre trabajo infantil y trabajo infantil doméstico, Asunción Paraguay, 2004, Oficina Internacional del Trabajo.

- CASTANHA, N. Hacia la definición de una Norma Modelo sobre Abuso y Explotación Sexual de Niños, Niñas y Adolescentes en las Américas. Montevideo, 2001. Documento de trabajo interno del Instituto Interamericano del Niño.

- CONVENIO SOBRE LA PROHIBICIÓN DE LAS PEORES FORMAS DE TRABAJO INFANTIL Y LA ACCIÓN INMEDIATA PARA SU ELIMINACIÓN. (Nota: Fecha de entrada en vigor: 19:11:2000) Lugar: Ginebra, Sesión de la Conferencia: 87. Fecha de adopción: 17:06:1999 Sujeto: Eliminación del trabajo infantil y protección de los niños y de los adolescentes Estatus: Instrumento actualizado. Este instrumento forma parte de los convenios fundamentales. La Conferencia General de la Organización Internacional del Trabajo: Convocada en Ginebra por el Consejo de Administración de la Oficina Internacional del Trabajo y congregada en dicha ciudad el $1{ }^{\circ}$ De junio de 1999 , en su octogésima séptima reunión.

- FALEIROS, Vicente. Redes de Explotación y Abuso Sexual y Redes de Protección, En: Para Combatir la Violencia (El Papel de la Familia y de la Asistencia Social en la Acción Junto a Niños y Adolescentes) Fundap, Brasil. 2000. Ministerio de la Providencia Social.

- FAZZIO, Adriana y SOKOLOVSKY, Jorge. Cuestiones de la Niñez (Aportes para la formulación de Políticas Públicas) 2006, Ed. Espacio. Argentina.

- MANEL Costas, Joan. Vidas explotadas, (la explotación infantil); México. 2008, Ediciones Formación Intervidas.

- MATA Y MARTÍN, Ricardo. Delincuencia Informática y Derecho Penal, Madrid, Edisofer Sl., 2001.

- ORNELAS, Carlos. Sistema Educativo Mexicano. (La transición de fin de siglo) México 1995, Fondo de Cultura Económica.

- PAVÓN VASCONCELOS, Francisco. Diccionario de Derecho Penal, México, 2003, $3^{\mathrm{a}}$. Edición, Porrúa.

- ROXIN, CLAUS. Derecho Penal. (Parte general), España, Tomo I, fundamentos de la estructura de la teoría del delito, Trad. Y Notas de Diego-Manuel Luzón Peña, Madrid, Civitas, 1997.

- ZAFFARONi EugeniO, Raúl. Derecho penal. (Parte general), México. vol. I, Cárdenas Editor y Distribuidor. 1988. 


\section{LEGISGRAFÍA}

- Constitución Política de los Estados Unidos Mexicanos, Cámara de Diputados del H. Congreso de la Unión, México.

- Ley Federal del Trabajo. Cámara de Diputados del H. Congreso de la Unión, México.

- Ley para la Protección de los Derechos de Niñas, Niños y Adolescentes Cámara de Diputados del H. Congreso de la Unión, México.

\section{CIBERGRAFÍA}

- BIBLIOTECA DE CONSULTA Microsoft ${ }^{\circledR}$ Encarta ${ }^{\circledR}$ 2003. (C) 1993-2002 Microsoft Corporation. Reservados todos los derechos.

- Com.mx.http://www.elsiglodetorreon.com.mx/noticia/440062.la-explotacion-infantil-enmexico.html.

- CONVENIO SOBRE LA EDAD MÍNIMA DE ADMISIÓN AL EMPLEO DE LOS MENORES. Instrumento actualizado como parte de los convenios fundamentales. OIT. http://www.unicef.org/mexico/spanish/mx_resources_138_OIT.pdf.

- CRÍTICA, LA SITUACIÓN LABORAL EN MÉXICO. Las violaciones a la Ley Federal de Trabajo (LFT) Una Constante. En: Diario digital "la jornada" http://www.jornada.unam. $\mathrm{mx} / 2008 / 02 / 11 /$ index.php? section $=$ sociedad\&article $=042 \mathrm{n} 1$ soc.

- DECLARACIÓN DE LOS DERECHOS DE LOS NIÑOS DE 1959. http://www. pequelandia.org/derechos/declaracion/.

- DECLARACION UNIVERSAL DE DERECHOS HUMANOS. 10 diciembre de1948. https:// www.agpd.es/portalwebAGPD/canaldocumentacion/legislacion/organismos_internacionales/ naciones_unidas/common/pdfs/D.1-cp--DECLARACI-OO-N-UNIVERSAL-DEDERECHOS-HUMANOS.pdf.

- DERECHOS Y OBLIGACIONES DE LOS NIÑOS Y LAS NIÑAS. EL DRAMA DEL TRABAJO INFANTIL EN MÉXICO. En: "ARTÍCULO Z". FONDO DE LAS NACIONES UNIDAS PARA LA INFANCIA (UNICEFF) http://www.cinu.org.mx/onu/estructura/mexico/fond/unicef.htm. http://www.articuloz.com/noticias-y-sociedad-articulosel-drama-del-trabajo-infantil-enmexico-424573.

http://www.cedhj.org.mx/derechos_humanos/cuales_son/ni\%F1os.html. http://www.idconline.com.mx/laboral/2012/11/30/publican-reforma-laboral. http://www.lajornadaguerrero.com.mx/2007/03/07/index.php?section=sociedad\&art icle $=006$ n 1 soc.

http://www.unicef.org/spanish/crc/http://www.unicef.org/spanish/crc/. http://www.unicef.org/spanish/rightsite/sowc/pdfs/panels/SOWC $\% 20$ all $\% 20$ panels\%20SP.pdf.

- INSTITUTO NACIONAL DE GEOGRAFÍA E INFORMÁTICA (INEGI) http:// cuentame.inegi.org.mx/poblacion/ninos.aspx?tema=P.

- LA EXPLOTACIÓN INFANTIL EN MEXICO. En “Diario el Siglo de Torreón”.

- LA EXPLOTACIÓN INFANTIL: http://www.youtube.com/watch?v=bsdKKfRp8BY[/ media.

- LA JORNADA DE GUERRERO. En México no se cumple la ley sobre el trabajo infantil: relator de la ONU.

- LOS PROTOCOLOS FACULTATIVOS DE LA CONVENCIÓN. La evolución de las normas internacionales sobre derechos de la infancia.

- MÉXICO EN CIFRAS. INEGI. http://www.inegi.org.mx/sistemas/mexicocifras/.

- NUEVOS SALARIOS MÍNIMOS 2013, Por Área Geográfica Generales y Profesionales. 
http://www.conasami.gob.mx/nvos_sal_2013.html.

- ORGANIZACIÓN INTERNACIONAL DEL TRABAJO. (OIT) http:/ /www.ilo.org/global/lang--es/index.htm\#a1.

- Peña Nieto, Enrique. LA REFORMA CONSTITUCIONAL EL ESTADO MEXICANO. http://www.presidencia.gob.mx/articulos-prensa/con-la-reforma-constitucional-el-estadomexicano-asume-plenamente-la-accion-rectora-y-reguladora-de-la-educacion-epn/.

- PROGRAMA INTERNACIONAL PARA LA ERRADICACIÓN DEL TRABAJO INFANTIL (IPEC). http://www.ilo.org/ipec/lang--es/index.htm\#a1.

- PROTECCIÓN INFANTIL. Contra el Abuso y la Violencia: http://www.unicef.org/ spanish/protection/index_childlabour.html.

- PUBLICAN REFORMA LABORAL. En IDCONLINE. RAMÍREZ CUEVAS. Jesús Los Niños empacadores, necesarios para el sostenimiento de Miles de Familias "Los cerillos de Wal-Mart” en: "Diario la Jornada digital". http://www.jornada.unam.mx/2005/08/07/mascuevas.html.

- RATIFICACIÓN DE MÉXICO de la Convención sobre los derechos del niño. Reforma laboral 2012, México. http://reformalaboralmexico.com/descarga-analisis/.

- SOLÍS QUIROGA, Héctor. Derechos del Menor de Edad. México. Biblioteca Jurídica Virtual, UNAM. http://www.juridicas.unam.mx/publica/librev/rev/facdermx/cont/166/ dtr/dtr12.pdf.

- VEN RIESGOS EN INICIATIVA PARA PROTECCIÓN DE LOS DERECHOS DE LA NIÑEZ. En SINEMBARGO.MX http:/ /www.sinembargo.mx/11-04-2012/203892. 